\title{
Avian Influenza H5N8 Outbreak in African Penguins (Spheniscus demersus), Namibia, 2019
}

\begin{abstract}
Molini Umberto, ${ }^{1}$ Gottlieb Aikukutu, ${ }^{2}$ Jean-Paul Roux, ${ }^{3}$ Jessica Kemper, ${ }^{4}$ Charles Ntahonshikira, ${ }^{1}$ Giuseppe Marruchella, ${ }^{1,5}$ Siegfried Khaiseb, ${ }^{2}$ Giovanni Cattoli, ${ }^{6}$ and William G. Dundon ${ }^{6,7}{ }^{1}$ Department $^{1}$ Pathobiology, School of Veterinary Medicine, Faculty of Agriculture and Natural Resources, University of Namibia, Neudamm Campus, Private Bag 13301, Windhoek, Namibia; ${ }^{2}$ Central Veterinary Laboratory (CVL), 24 Goethe Street, Private Bag 18137, Windhoek, Namibia; ${ }^{3}$ Ecosystem Section, Lüderitz Marine Research, Ministry of Fisheries and Marine Resources, PO Box 394, Lüderitz, Namibia; ${ }^{4}$ African Penguin Conservation Project, PO Box 583, Lüderitz, Namibia; ${ }^{5}$ Faculty of Veterinary Medicine, University of Teramo, Loc. Piano d'Accio S.P. 18, 64100, Teramo, Italy; ${ }^{6}$ Animal Production and Health Laboratory, Animal Production and Health Section, Joint FAO/IAEA Division, Department of Nuclear Sciences and Applications, International Atomic Energy Agency, PO Box 100, 1400 Vienna, Austria; ${ }^{7}$ Corresponding author (email: W.Dundon@iaea.org)
\end{abstract}

Aвstract: In January 2019, high mortalities were reported among African Penguins (Spheniscus demersus) in a breeding colony on Halifax Island, Namibia, Africa. Analysis of samples by reverse transcription quantitative PCR indicated the presence of highly pathogenic avian influenza (HPAI) subtype H5N8. Sequence analysis of the hemagglutinin and neuraminidase genes confirmed the presence of the virus in the birds and its high similarity to HPAI subtype $\mathrm{H} 5 \mathrm{~N} 8$ identified in South Africa in 2017. There have been no previous reports of HPAI H5N8 in Namibia.

Key words: Highly pathogenic avian influenza, H5N8, Namibia, outbreak, penguins.

The African penguin (Spheniscus demersus) is an endangered species that is found only in southern African waters with a breeding range that extends from the Eastern Cape Province, South Africa, to southern Namibia. In Namibia, the penguin population has been declining throughout the 20th century, and in South Africa, a rapid population decline has occurred since 2000 , believed to be primarily due to food availability and environmental degradation (Kemper et al. 2001; Crawford et al. 2011).

Early in January 2019, an unusually high mortality of African Penguins was noted during routine coastal monitoring near Halifax Island, Namibia, Africa (26 $39^{\prime} 4^{\prime \prime} \mathrm{S}$, $15^{\circ} 4^{\prime} 48^{\prime \prime} \mathrm{E}$ ), which is a protected penguin breeding site about $100 \mathrm{~m}$ from the mainland. The last complete assessment for Halifax Island for the year 2014 showed a population of 6,930 penguins in adult plumage, as calculated from serial counts of molting birds
(Kemper et al. 2007), including 1,400 breeding pairs. All but a few of the dead birds observed were in adult plumage. African Penguins attain the typical adult plumage between 1 and 2 yr of age, but most birds only start breeding in their fourth to sixth year (Whittington et al. 2005). As many dead penguins were found close to the breeding colonies where nonbreeding penguins generally do not venture, it was assumed that that a large proportion of the mortalities were breeding birds.

By 17 January 2019, more than 200 penguin carcasses had been retrieved, several sick birds were seen on the island, and more carcasses were reported by tour boats in the surrounding waters. Retrospective examination of daily photographs of the island shoreline showed that this mortality event had started in the first half of December 2018. By the second half of February 2019, more than 350 penguin carcasses had been found on Halifax Island, confirming that this event constituted the most severe mortality event on record for this species in Namibia. An official report was made to the World Organization for Animal Health (OIE) by Namibian authorities (OIE 2019).

The carcasses of five adult penguins (four males and one female) were collected, refrigerated, and sent to the Central Veterinary Laboratory (CVL; Windhoek, Namibia) for necropsy between January and February 2019. The carcasses were promptly frozen on arrival at the CVL. In addition, the liver of one dead penguin and three cloacal swabs 
obtained from birds that had shown signs of illness prior to death, which included emaciation, torticollis, twitching, incoordination, corneal opacity, and lethargic or comatose behavior, were submitted to the CVL (Table $1)$.

On external inspection, the carcasses appeared normal, although a grayish-greenish soiling of the pericloacal region was observed in two cases. Necropsy revealed fibrinous strands in the coelomic cavity, diffuse congestion of the viscera, and segmental hemorrhages of the gut in all cases (Fig. 1).

We extracted RNA from the liver sample using a Maxwell 16 LEV SimplyRNA Tissue Purification Kit (Promega, Madison, Wisconsin, USA) according to the manufacturer's instructions, while the cloacal swabs were suspended and centrifuged in $2 \mathrm{~mL}$ of sterile phosphate buffered saline. We then extracted RNA from $300 \mu \mathrm{L}$ of the suspension using a Maxwell 16 Viral Total Nucleic Acid Purification Kit (Promega) following to the manufacturer's instructions. The matrix protein gene (M1) and the hemagglutinin H5 gene of influenza A virus were detected by reverse transcription quantitative PCR (RT-qPCR), using both the commercial genesig ${ }^{\circledR}$ Advanced Kit for Influenza A Virus (M1) and genesig ${ }^{\circledR}$ Advanced Kit for Avian Influenza A Virus subtype H5 (Primerdesign Ltd., Southampton, UK). The neuraminidase (NA) gene (N8) was detected using an RT-qPCR-based low-density array for subtyping avian influenza viruses according to the method proposed by Hoffmann et al. (2016).

For further characterization of the viruses, a 1,118-base-pair (bp) fragment of the hemagglutinin (HA) gene was amplified using the One-Step RT-PCR kit (Qiagen, Hilden, Germany) and the following primers: H5-2F (5'TCATCATTCCAACAATGCAGA-3') and H5-3R (5'-TGCAAATTCTGCACTGTAACG-3'). For the NA gene, two pairs of primers were used to amplify two overlapping sequence fragments of $654 \mathrm{bp}$ and $833 \mathrm{bp}$, respectively, covering a total of $1,413 \mathrm{bp}$ of the NA gene. These primer pairs were (pair 1) N8-1F (5' - ATGAATCCAAATCAGAAAATA$\left.3^{\prime}\right)$ and N8-1R (5'-CGCCCAGGAGTTAA-
Table 1. Samples from African Penguin (Spheniscus demersus) infected with highly pathogenic avian influenza (HPAI) subtype H5N8 in an outbreak on Halifax Island, Namibia, Africa, in January 2019.

\begin{tabular}{|c|c|c|c|c|}
\hline $\begin{array}{c}\text { Reference } \\
\text { number }\end{array}$ & $\begin{array}{l}\text { Collection } \\
\text { date (2019) }\end{array}$ & Sample & Gene & $\begin{array}{c}\text { GenBank } \\
\text { accession } \\
\text { number }\end{array}$ \\
\hline \multirow[t]{2}{*}{$146 \mathrm{~T}$} & \multirow[t]{2}{*}{17 January } & \multirow[t]{2}{*}{ Liver } & H5 & MK571753 \\
\hline & & & N8 & MK898935 \\
\hline \multirow[t]{2}{*}{$146 \mathrm{~S}$} & \multirow[t]{2}{*}{17 January } & \multirow[t]{2}{*}{ Cloacal swab } & $\mathrm{H} 5$ & MK571754 \\
\hline & & & N8 & MK898936 \\
\hline \multirow[t]{2}{*}{$218(1)$} & \multirow[t]{2}{*}{05 February } & \multirow[t]{2}{*}{ Cloacal swab } & $\mathrm{H} 5$ & MK571806 \\
\hline & & & N8 & MK898937 \\
\hline \multirow[t]{2}{*}{$218(2)$} & \multirow[t]{2}{*}{05 February } & \multirow[t]{2}{*}{ Cloacal swab } & H5 & MK571807 \\
\hline & & & N8 & MK898938 \\
\hline
\end{tabular}

CAACAT-3') and (pair 2) N8-2F (5'CGCCCAGGAGTTAACAACAT-3') and N83R (5'-TTACATCTTATCGATGTCAA-3'). We used the following thermal profile for all primer pairs: reverse transcription at $50 \mathrm{C}$ for $30 \mathrm{~min}$, initial denaturation at $95 \mathrm{C}$ for $15 \mathrm{~min}$, and then 40 cycles of denaturation at $95 \mathrm{C}$ for $30 \mathrm{~s}$, annealing at $55 \mathrm{C}$ for $1 \mathrm{~min}$, and elongation at $72 \mathrm{C}$ for $2 \mathrm{~min}$, followed by a final elongation at $72 \mathrm{C}$ for $7 \mathrm{~min}$. Amplified fragments were visualized on $1.5 \%$ to $2 \%$ agarose gels. Positive RT-PCR amplicons were purified using a QIAquick PCR Purification Kit (Qiagen) and were sent to LGC Genomics (Berlin, Germany) for sequencing. All of the HA and NA sequences generated were deposited in GenBank (Table 1). The analysis of the translated sequence of the HA gene revealed a polybasic stretch of amino acids immediately preceding the cleavage site, PLREKRRKR/GLF, confirming that the viruses were highly pathogenic.

Phylogenetic trees were estimated using the maximum likelihood method available in MEGA 6 (Tamura et al. 2013), employing the Kimura two-parameter model of nucleotide substitution with uniform rates among sites and 1,000 bootstrap replications incorporating the HA and NA sequences generated in this study with those available in GenBank (accession numbers are shown in Fig. 2A, B).

From the phylogenetic analyses, the Namibian viruses belong to highly pathogenic avian 

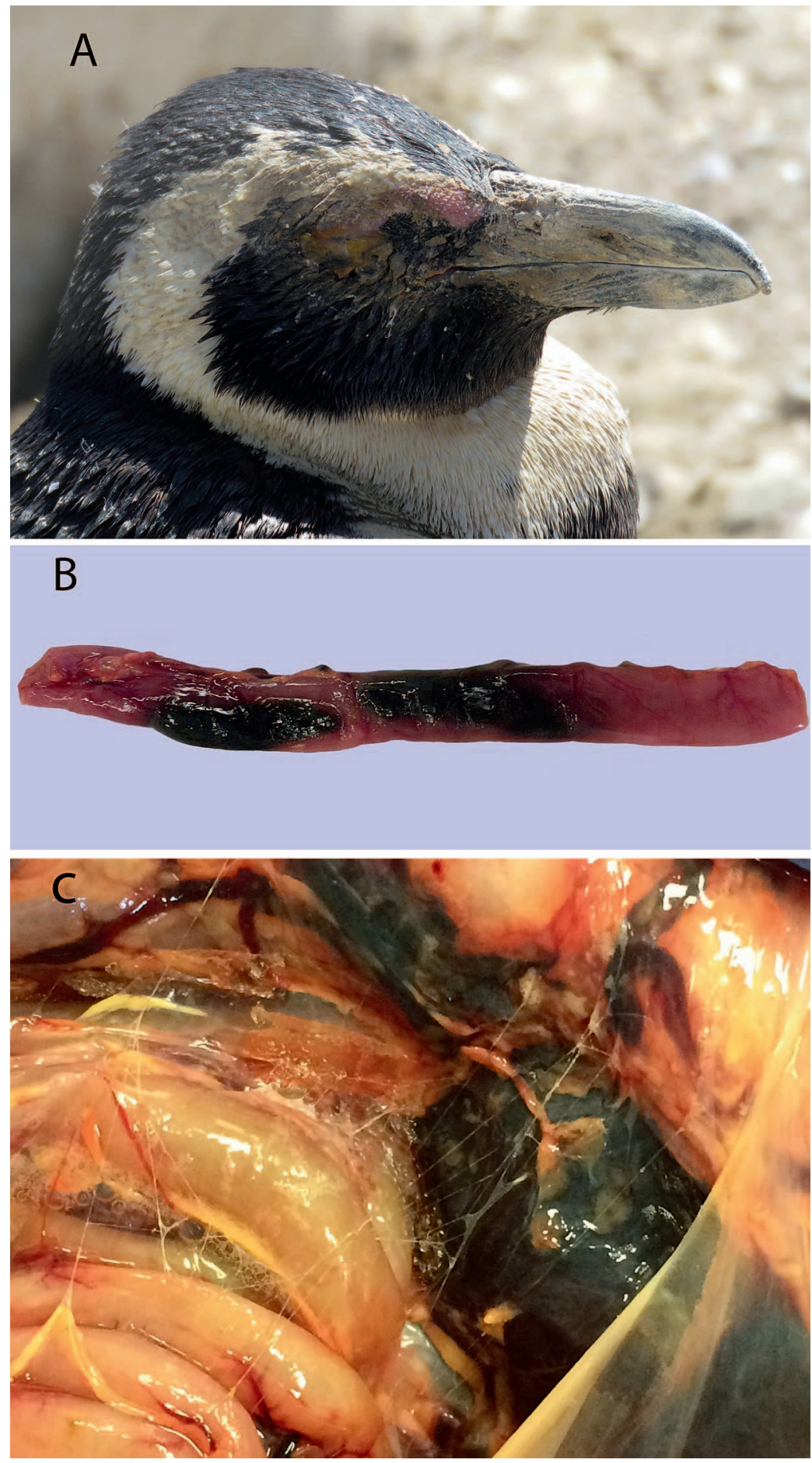

Figure 1. Gross and necropsy observations of African Penguin (Spheniscus demersus) infected with highly pathogenic avian influenza (HPAI) subtype H5N8 in an outbreak on Halifax island, Namibia, Africa, in January 2019. (A) Adult African Penguin showing excessive mucus around the eyes. (B) Duodenum of an adult, male penguin. The intestinal walls are diffusely hyperemic, and some segments show a prominent hemorrhagic appearance. (C) Coelomic cavity of adult, male penguin. Numerous fibrinous strands are seen, mainly between the intestinal loops 


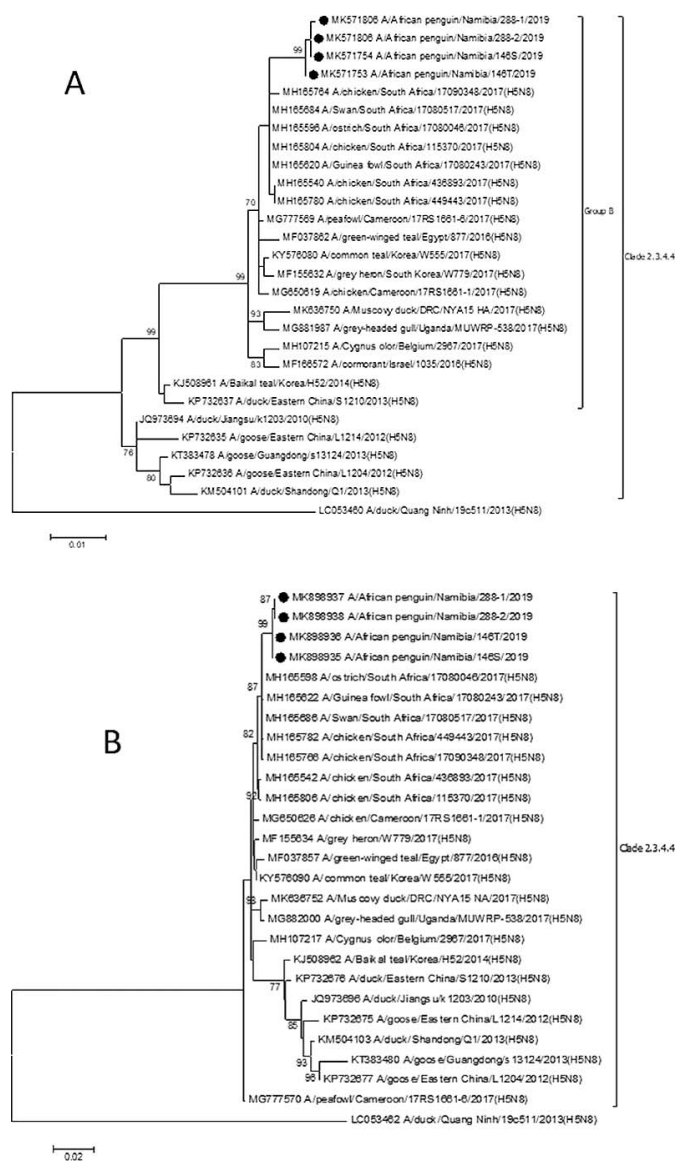

Figure 2. Maximum likelihood phylogenetic tree of (A) partial H5 gene sequence (1,061 base pairs) and (B) partial N8 gene sequence (1,394 base pairs) from the samples collected from African Penguins (Spheniscus demersus) infected with highly pathogenic avian influenza (HPAI) subtype H5N8 in an outbreak on Halifax Island, Namibia, Africa, in January 2019, and similar sequences available in GenBank. The sequences from this study are shown by filled black circles. Clades and groupings are shown. Only bootstrap values greater than $70 \%$ are shown.

influenza (HPAI) H5N8 clade 2.3.4.4 B (Fig. 2A, B). The HPAI H5N8 2.3.4.4 B viruses were responsible for outbreaks of HPAI in Asia, Europe, and Africa during 2016-17 (Lee et al. 2017). In southern Africa, Zimbabwe reported HPAI H5N8 clade 2.3.4.4 B in commercial poultry in June 2017. In the same month, South Africa confirmed the presence of the virus in a broiler breeder farm and then identified the virus in backyard hobby and zoo collections, commercial poultry and ostrich farms, and wild birds including African Penguins (OIE 2017; Abolnik et al. 2019). Specifically, between January 2018 and October 2018, deaths due to HPAI H5N8 clade 2.3.4.4 B occurred in African Penguins in the Western and Eastern Cape Provinces. Further investigation by the South African authorities revealed that distinct HPAI H5N8 clade 2.3.4.4 B variants were responsible for the initial outbreaks in the country and that they were not directly related to the viruses identified in Zimbabwe but shared recent common ancestors with HPAI H5N8 clade 2.3.4.4 B viruses from West Africa. As such, wild birds were strongly implicated in the introduction of HPAI H5N8 clade 2.3.4.4 $\mathrm{B}$ to the region (Abolnik et al. 2019).

The Namibian viruses were similar (HA: $99.5 \%$, NA: $99.3 \%$ ) but not identical to the South African viruses (Fig. 2). Since there were no sequences available from the viruses identified in Zimbabwe and no reports to date of $\mathrm{H} 5 \mathrm{~N} 8$ from neighboring Botswana, Angola, or Zambia, it was not possible to confirm the exact origin of the HPAI H5N8 in Namibia. It is possible that the virus introduced into the Halifax Island colony originated from countries other than South Africa. The generation of a full genomic sequence analysis of the Namibian isolates, which was beyond the scope of this present work, would allow a more detailed comparison with the HPAIH5N8 clade 2.3.4.4 B virus that infected African Penguins in 2017 in South Africa and determination of whether the outbreak on Halifax Island was due to the movement and spread of virus between the South African and Namibian colonies or the result of a new introduction of the virus.

The origin of the outbreak remains unclear, but the virus was probably spread through regional movements of wild birds such as Greater-crested (Swift) Terns (Thalasseus bergii). During the H5N8 outbreaks in South Africa in 2017-18, terns were the most affected wild bird species. In May 2018, about 20 swift terns roosting at Mercury Island, another Namibian seabird breeding island roughly $105 \mathrm{~km}$ north of Halifax Island, died from unknown causes after displaying symp- 
toms of avian influenza (R. Jones pers. comm.), although testing of these birds, and therefore confirmation of the cause of death, was not possible.

Like most seabirds, African Penguins are long-lived, with late maturation and relatively low reproductive rates (Kemper et al. 2007). They are considered locally and globally endangered (IUCN 2019). A loss of several hundred birds, including breeding birds, therefore has long-term implications for the demography of the already tenuous regional population of the species. Although this outbreak appeared to be restricted to African Penguins, the outbreak in South Africa's Cape in 2017-18 showed that other coastal bird species may be affected. Namibia's seabird breeding islands support significant numbers of endangered Cape Gannets (Morus capensis), and Bank Cormorants (Phalacrocorax neglectus; IUCN 2019). An outbreak of $\mathrm{H} 5 \mathrm{~N} 8$ in these species in Namibia could be catastrophic, and in a worst-case scenario, it could threaten Bank Cormorants with extinction.

Finally, no other wild birds that are resident on the Halifax Island, including Kelp Gulls (Larus dominicanus), Crowned Comorants (Microcarbo coronatus), Swift Terns, Hartlaub's Gulls (Chroicocephalus hartlaubii), and African Oystercatchers (Haematopus moquini), have manifested disease symptoms. A serologic investigation of these birds could determine whether they have been infected with avian influenza virus and if they could be a potential risk for the spread of the virus to the mainland or other islands.

The sequences from this study were generated through the Sequencing Services of the Animal Production and Health Sub-programme of the Joint Food and Agricultural Organization of the United Nations/International Atomic Energy Agency (IAEA) Division in Vienna, Austria. This study was supported by funds from the IAEA Peaceful Uses Initiative (PUI) VETLAB Network.

\section{LITERATURE CITED}

Abolnik C, Pieterse R, Peyrot BM, Choma P, Phiri TP, Ebersohn K, van Heerden CV, Vorster AA, van der Zel G, Geertsma PJ, et al. 2019. The incursion and spread of highly pathogenic avian influenza H5N8 clade 2.3.4.4 within South Africa. Avian Dis 63:149 156.

Crawford RJM, Altwegg R, Barham BJ, Barham PJ, Durant JM, Dyer BM, Geldenhuys D, Makhado AB, Pichegru L, Ryan PG, et al. 2011. Collapse of South Africa's penguins in the early 21st century. Afr J Mar Sci 33:139-156.

Hoffmann B, Hoffmann D, Henritzi D, Beer M, Harder TC. 2016. Riems influenza A typing array (RITA): An RT-qPCR-based low density array for subtyping avian and mammalian influenza A viruses. Sci Rep 6:27211.

IUCN (International Union for Conservation of Nature). 2019. The IUCN Red List of Threatened Species. Version 2019-1. http://www.iucnredlist.org. Accessed March 2019.

Kemper J, Roux J-P, Bartlett PA, Chesselet YJ, Delport JA, James JA, Jones R, Underhill LG, Uhongora NN, Wepener S. 2007. The African Penguin Spheniscus demersus: Population estimates, trends, adult survival and age structure from moult and nest counts. In: Final report of the BCLME (Benguela Current Large Marine Ecosystem) project on top predators as biological indicators of ecosystem change in the BCLME, Kirkman SP, editor. Avian Demography Unit, University of Cape Town, Cape Town, South Africa, pp. 69-76.

Kemper J, Roux J-P, Bartlett PA, Chesselet YJ, James JAC, Jones R, Wepener S, Molloy FJ. 2001. Recent population trends of African Penguins Spheniscus demersus in Namibia. S Afr J Marine Sci 23:429-434.

Lee DH, Bertran K, Kwon JH, Swayne DE. 2017. Evolution, global spread, and pathogenicity of highly pathogenic avian influenza $\mathrm{H} 5 \mathrm{Nx}$ clade 2.3.4.4. J Vet Sci 18:269-280.

OIE (Revue Scientifique et Technique de l'Office International des Epizooties). 2017. WAHIS country report, South Africa. http://www.oie.int/wahis_2/ public/wahid.ph p/Countryinformation/ Countryreports. Accessed May 2019.

OIE. 2019. WAHIS country report, Namibia. http://www. oi e.int/wahis_2/public/wahid.ph p/ Countryinformation/Countryreports. Accessed May 2019.

Tamura K, Stecher G, Peterson D, Filipski A, Kumar S. 2013. MEGA6: Molecular evolutionary genetics analysis version 6.0. Mol Biol Evol 30:2725-2729.

Whittington P, Klages N, Crawford R, Wolfaardt A, Kemper J. 2005. Age at first breeding of the African Penguin. Ostrich 76:14-20.

Submitted for publication 20 March 2019.

Accepted 23 May 2019. 